Research Article

\title{
Common Best Proximity Coincidence Point Theorem for Dominating Proximal Generalized Geraghty in Complete Metric Spaces
}

\author{
Anchalee Khemphet $\mathbb{D}^{1,2}$ Pharunyou Chanthorn $\mathbb{D}$, ${ }^{1,2}$ and Narawadee Phudolsitthiphat $\mathbb{D}^{1,2}$ \\ ${ }^{1}$ Data Science Research Center, Department of Mathematics, Faculty of Science, Chiang Mai University, Chiang Mai 50200, Thailand \\ ${ }^{2}$ Department of Mathematics, Faculty of Science, Chiang Mai University, Chiang Mai 50200, Thailand
}

Correspondence should be addressed to Narawadee Phudolsitthiphat; narawadee_n@hotmail.co.th

Received 1 June 2020; Accepted 4 July 2020; Published 1 August 2020

Guest Editor: Erdal Karapinar

Copyright (c) 2020 Anchalee Khemphet et al. This is an open access article distributed under the Creative Commons Attribution License, which permits unrestricted use, distribution, and reproduction in any medium, provided the original work is properly cited.

In this paper, we introduce a new concept of dominating proximal generalized Geraghty for two mappings and prove the existence and uniqueness of a common best proximity coincidence point in complete metric spaces. And also, we give an example for the main theorems. The main theorem is a generalization and improvement of some well-known theorems.

\section{Introduction}

The best proximity point problems have been attracted to many researchers as there are various applications in realworld problems. The optimization problem is one of the applications that benefit from the best proximity point theory. In other words, it helps finding an approximate solution to the fixed point problems even the mapping itself does not have a fixed point (see [1-23]). In literature, most works focus on suggesting suitable conditions to promise the existence of approximate optimal solutions. These results give the best proximity point theorem in a variety of approaches.

For instance, the work of Geraghty [24] is one of several important results inspired by the Banach contraction principle for the existence of fixed points for self mappings in metric spaces. In fact, this result generalizes previous concepts by introducing the class $\Theta$ of all mappings $\theta:[0, \infty) \longrightarrow[0,1)$ such that

$$
\lim _{n \rightarrow \infty} \theta\left(t_{n}\right)=1 \Longrightarrow \lim _{n \rightarrow \infty} t_{n}=0 .
$$

In 2012, Basha [25] proposed a result on common best proximity points with a property called proximal commutativity of mappings. Later, Kumam and Mongkolekeha [26] considered common best proximity point theorems for proximity commuting mappings. In addition, this study has been done according to Geraghty's work in complete metric spaces. After that, Chen [27] established the definition of a mapping $T$ generally dominates a mapping $S$ and accomplished theorems of existence and uniqueness of common best proximity points for a pair of nonself mappings. Lately, Ayari [28] improved the class $\Theta$ of Geraghty and defined a new class $\mathscr{B}$ of the mappings $\beta:[0, \infty) \longrightarrow[0,1]$ such that

$$
\lim _{n \rightarrow \infty} \beta\left(t_{n}\right)=1 \Longrightarrow \lim _{n \rightarrow \infty} t_{n}=0 .
$$

Accordingly, the existence and uniqueness of best proximity points is guaranteed for $\alpha$-proximal Geraghty nonself mappings on a closed subset of a complete metric space.

To generalize previous results, we are interested to extend our study to common best proximity coincidence points for two mappings under certain conditions. Specifically, we investigate the existence and uniqueness of common best proximity coincidence points for any pairs of two mappings that are dominating proximal generalized Geraghty on a complete metric space. In particular, this work is organized into three sections. First, the motivation of the present study is given as described above. Next, we recall some essential 
definitions needed in our work. In Section 3, a new concept of dominating proximal generalized Geraghty for two mappings is introduced. Then, we show that a common best proximity coincidence point of these mappings uniquely exists under some additional assumptions. Moreover, an example is provided to support the main result. Lastly, we consider some further results following from our main theorem.

\section{Preliminaries}

In this section, we review some notations and important definitions to be used in the next section. Let $(A, B)$ be a pair of nonempty subsets of a metric space $(X, d)$. We adopt the following notations:

$d(A, B):=\inf \{d(a, b): a \in A, b \in B\}$,

$A_{0}:=\{a \in A$ : there exists $b \in B$ such that $d(a, b)=d(A, B)\}$,

$B_{0}:=\{b \in B$ : there exists $a \in A$ such that $d(a, b)=d(A, B)\}$.

Definition 1 (see $[1,26,29]$ ). Let $S, T: A \longrightarrow B$ and $g: A$ $\longrightarrow A$ be mappings.

An element $x^{*} \in A$ is said to be

(i) A best proximity point of $T$ if

$$
d\left(x^{*}, T x^{*}\right)=d(A, B)
$$

(ii) A best proximity coincidence point of the pair $(g, T)$ if

$$
d\left(g x^{*}, T x^{*}\right)=d(A, B)
$$

(iii) A common best proximity coincidence point of the pair $(S, T)$ if

$$
d\left(x^{*}, S x^{*}\right)=d(A, B)=d\left(x^{*}, T x^{*}\right)
$$

Definition 2 (see [29]). Let $S, T: A \longrightarrow B$ be mappings. A pair $(S, T)$ is said to commute proximally if for each $x, u, v \in A$,

$$
d(u, S x)=d(v, T x)=d(A, B) \text { implies } S v=T u .
$$

\section{Main Results}

In this section, we introduce a class of pairs of some proximal generalized Geraghty contractions with dominating property and prove common best proximity theorem for this class.

Definition 3. Let $S, T: A \longrightarrow B$ be mappings. A pair $(S, T)$ is said to be dominating proximal generalized Geraghty if there exists $\beta \in \mathscr{B}$ such that for each $x_{1}, x_{2}, u_{1}, u_{2}, v_{1}, v_{2} \in A$,

$$
d\left(u_{1}, S x_{1}\right)=d\left(u_{2}, S x_{2}\right)=d(A, B)=d\left(v_{1}, T x_{1}\right)=d\left(v_{2}, T x_{2}\right),
$$

implies

$$
d\left(u_{1}, u_{2}\right) \leq \beta\left(M\left(v_{1}, v_{2}, u_{1}, u_{2}\right)\right) M\left(v_{1}, v_{2}, u_{1}, u_{2}\right),
$$

where $M\left(v_{1}, v_{2}, u_{1}, u_{2}\right)=\max \left\{d\left(v_{1}, v_{2}\right), d\left(v_{1}, u_{1}\right), d\left(v_{2}\right.\right.$, $\left.\left.u_{2}\right),\left(\left(d\left(v_{1}, u_{2}\right)+d\left(v_{2}, u_{1}\right)\right) / 2\right)\right\}$.

Theorem 4. Let $(A, B)$ be a pair of nonempty subsets of a complete metric space $(X, d)$, and let $S, T: A \longrightarrow B$ be mappings. Suppose that the pair $(S, T)$ is dominating proximal generalized Geraghty. Assume that $A_{0}$ and $B_{0}$ are nonempty such that $A_{0}$ is closed. If the following assertions hold:

(i) $S\left(A_{0}\right) \subseteq B_{0}$ and $S\left(A_{0}\right) \subseteq T\left(A_{0}\right)$

(ii) $S$ and $T$ are continuous

(iii) S and T commute proximally

then there is only one common best proximity coincidence point $x^{*}$ of $(S, T)$ in $A$.

Proof. Let $x_{0}$ be a fixed element in $A_{0}$. From the assumption that $S\left(A_{0}\right) \subseteq T\left(A_{0}\right)$, we get that for each element $x \in A_{0}$, there is an element $y \in A_{0}$ such that $S x=T y$. Then, we obtain a sequence $\left\{x_{n}\right\}$ in $A_{0}$ satisfying

$$
S x_{n}=T x_{n+1} \text {. }
$$

for each $n \geq 0$. Since $S\left(A_{0}\right) \subseteq B_{0}$, there exists an element $u_{n} \in A_{0}$ such that

$$
d\left(u_{n}, S x_{n}\right)=d(A, B),
$$

for all $n \geq 0$. Further, we obtain that

$$
d(A, B)=d\left(u_{n}, S x_{n}\right)=d\left(u_{n}, T x_{n+1}\right),
$$

for all $n \geq 0$.

Our first goal is to show that $S u=T u$ for some $u \in A_{0}$.

In the case that $u_{n_{0}}=u_{n_{0}+1}$ for some $n_{0} \geq 0$, by (11) and (12), we get that

$$
d\left(u_{n_{0}+1}, S x_{n_{0}+1}\right)=d(A, B)=d\left(u_{n_{0}}, S x_{n_{0}}\right)=d\left(u_{n_{0}}, T x_{n_{0}+1}\right) .
$$

Since $S$ and $T$ commute proximally, $S\left(u_{n_{0}}\right)=T\left(u_{n_{0}+1}\right)=$ $T\left(u_{n_{0}}\right)$, and so we are done.

Now, for the harder part, assume that $u_{n} \neq u_{n+1}$ for all $n$ $\geq 0$. From (12), note that

$d\left(u_{n}, S x_{n}\right)=d\left(u_{n+1}, S x_{n+1}\right)=d(A, B)=d\left(u_{n-1}, T x_{n}\right)=d\left(u_{n}, T x_{n+1}\right)$,

for all $n \geq 1$. Since $(S, T)$ is dominating proximal generalized Geraghty, we have that 


$$
\begin{aligned}
d\left(u_{n}, u_{n+1}\right) & \leq \beta\left(M\left(u_{n-1}, u_{n}, u_{n}, u_{n+1}\right)\right) M\left(u_{n-1}, u_{n}, u_{n}, u_{n+1}\right) \\
& \leq M\left(u_{n-1}, u_{n}, u_{n}, u_{n+1}\right) .
\end{aligned}
$$

\section{Consider that}

$$
\begin{aligned}
M & \left(u_{n-1}, u_{n}, u_{n}, u_{n+1}\right) \\
& =\max \left\{d\left(u_{n-1}, u_{n}\right), d\left(u_{n}, u_{n+1}\right), \frac{d\left(u_{n-1}, u_{n+1}\right)}{2}\right\} \\
& \leq \max \left\{d\left(u_{n-1}, u_{n}\right), d\left(u_{n}, u_{n+1}\right), \frac{d\left(u_{n-1}, u_{n}\right)+d\left(u_{n}, u_{n+1}\right)}{2}\right\} \\
& =\max \left\{d\left(u_{n-1}, u_{n}\right), d\left(u_{n}, u_{n+1}\right)\right\} \leq M\left(u_{n-1}, u_{n}, u_{n}, u_{n+1}\right) .
\end{aligned}
$$

This implies that $M\left(u_{n-1}, u_{n}, u_{n}, u_{n+1}\right)=\max \left\{d\left(u_{n-1}\right.\right.$, $\left.\left.u_{n}\right), d\left(u_{n}, u_{n+1}\right)\right\}$ for all $n \geq 1$. to 0 .

Next, we prove that the sequence $\left\{d\left(u_{n}, u_{n+1}\right)\right\}$ converges

Consider the following two cases.

Case 1. $M\left(u_{n-1}, u_{n}, u_{n}, u_{n+1}\right)=d\left(u_{n-1}, u_{n}\right)$.

From (15), we have that

$$
d\left(u_{n}, u_{n+1}\right) \leq \beta\left(d\left(u_{n-1}, u_{n}\right)\right) d\left(u_{n-1}, u_{n}\right) \leq d\left(u_{n-1}, u_{n}\right),
$$

for all $n \geq 1$. Therefore, $\left\{d\left(u_{n}, u_{n+1}\right)\right\}$ is a nonincreasing sequence which is bounded below, and so it is convergent. To obtain that $\lim _{n \rightarrow \infty} d\left(u_{n}, u_{n+1}\right)=0$, suppose on the contrary that $\lim _{n \rightarrow \infty} d\left(u_{n}, u_{n+1}\right)>0$. By (17), letting $n \longrightarrow \infty$ implies

$$
1=\lim _{n \rightarrow \infty} \frac{d\left(u_{n}, u_{n+1}\right)}{d\left(u_{n-1}, u_{n}\right)} \leq \lim _{n \rightarrow \infty} \beta\left(d\left(u_{n-1}, u_{n}\right)\right) \leq 1
$$

Since $\lim _{n \rightarrow \infty} \beta\left(d\left(u_{n-1}, u_{n}\right)\right)=1$, by the definition of $\beta$,

$$
0<\lim _{n \rightarrow \infty} d\left(u_{n}, u_{n+1}\right)=\lim _{n \rightarrow \infty} d\left(u_{n-1}, u_{n}\right)=0
$$

which is a contradiction. Thus, we get that $\lim _{n \rightarrow \infty} d\left(u_{n}\right.$, $\left.u_{n+1}\right)=0$.

Case 2. $M\left(u_{n-1}, u_{n}, u_{n}, u_{n+1}\right)=d\left(u_{n}, u_{n+1}\right)$. Similarly, by (15), we have that

$$
d\left(u_{n}, u_{n+1}\right) \leq \beta\left(d\left(u_{n}, u_{n+1}\right)\right) d\left(u_{n}, u_{n+1}\right) \leq d\left(u_{n}, u_{n+1}\right) .
$$

Since $d\left(u_{n}, u_{n+1}\right)>0$ for all $n \geq 0$, we get that $1 \leq \beta\left(d\left(u_{n}\right.\right.$, $\left.\left.u_{n+1}\right)\right) \leq 1$, and hence, $\lim _{n \rightarrow \infty} \beta\left(d\left(u_{n}, u_{n+1}\right)\right)=1$. By the definition of $\beta$, we also have that $\lim _{n \rightarrow \infty} d\left(u_{n}, u_{n+1}\right)=0$.
Due to both cases, we obtain the desired limit

$$
\lim _{n \rightarrow \infty} d\left(u_{n}, u_{n+1}\right)=0
$$

Now, we claim that $\left\{u_{n}\right\}$ is a Cauchy sequence.

Suppose contradiction, that is, $\left\{u_{n}\right\}$ is not a Cauchy sequence. Then, there exists $\varepsilon>0$ such that there are subsequences $\left\{u_{m_{k}}\right\}$ and $\left\{u_{n_{k}}\right\}$ of $\left\{u_{n}\right\}$ so that for all $k \in \mathbb{N}$ with $m_{k}>n_{k}>k$, we obtain

$$
d\left(u_{m_{k}}, u_{n_{k}}\right) \geq \varepsilon
$$

In addition, we can choose the smallest $n_{k}$ satisfying (22) for all $k \in \mathbb{N}$ so that

$$
d\left(u_{m_{k}}, u_{n_{k}-1}\right)<\varepsilon .
$$

By using (22) and (23), we have that

$\varepsilon \leq d\left(u_{m_{k}}, u_{n_{k}}\right) \leq d\left(u_{m_{k}}, u_{n_{k}-1}\right)+d\left(u_{n_{k}-1}, u_{n_{k}}\right)<\varepsilon+d\left(u_{n_{k}-1}, u_{n_{k}}\right)$.

Since $\lim _{n \rightarrow \infty} d\left(u_{n}, u_{n+1}\right)=0$, taking the limit as $k \longrightarrow \infty$ in (24) implies

$$
\lim _{k \rightarrow \infty} d\left(u_{m_{k}}, u_{n_{k}}\right)=\varepsilon
$$

Consider, by the triangular inequality, that

$d\left(u_{m_{k}}, u_{n_{k}}\right) \leq d\left(u_{m_{k}}, u_{m_{k}+1}\right)+d\left(u_{m_{k}+1}, u_{n_{k}+1}\right)+d\left(u_{n_{k}+1}, u_{n_{k}}\right)$.

Consequently, $\varepsilon=\lim _{k \rightarrow \infty} d\left(u_{m_{k}}, u_{n_{k}}\right) \leq \lim _{k \rightarrow \infty} d\left(u_{m_{k}+1}\right.$, $\left.u_{n_{k}+1}\right)$.

In the same way, we get that

$d\left(u_{m_{k}+1}, u_{n_{k}+1}\right) \leq d\left(u_{m_{k}+1}, u_{m_{k}}\right)+d\left(u_{m_{k}}, u_{n_{k}}\right)+d\left(u_{n_{k}}, u_{n_{k}+1}\right)$,

and so $\lim _{k \rightarrow \infty} d\left(u_{m_{k}+1}, u_{n_{k}+1}\right) \leq \lim _{k \rightarrow \infty} d\left(u_{m_{k}}, u_{n_{k}}\right)=\varepsilon$.

Thus,

$$
\lim _{k \rightarrow \infty} d\left(u_{m_{k}+1}, u_{n_{k}+1}\right)=\varepsilon .
$$

Since $\left\{u_{m_{k}}\right\}$ and $\left\{u_{n_{k}}\right\}$ satisfy equations (11) and (12), we obtain that

$$
\begin{gathered}
d\left(u_{n_{k}+1}, S x_{n_{k}+1}\right)=d(A, B)=d\left(u_{n_{k}}, T x_{n_{k}+1}\right), \\
d\left(u_{m_{k}+1}, S x_{m_{k}+1}\right)=d(A, B)=d\left(u_{m_{k}}, T x_{m_{k}+1}\right),
\end{gathered}
$$

for each $k \geq 1$. Since $(S, T)$ is dominating proximal generalized Geraghty, 


$$
\begin{array}{r}
d\left(u_{n_{k}+1}, u_{m_{k}+1}\right) \leq \beta\left(M\left(u_{n_{k}}, u_{m_{k}}, u_{n_{k}+1}, u_{m_{k}+1}\right)\right) \\
\cdot M\left(u_{n_{k}}, u_{m_{k}}, u_{n_{k}+1}, u_{m_{k}+1}\right),
\end{array}
$$

where

$$
\begin{gathered}
M\left(u_{n_{k}}, u_{m_{k}}, u_{n_{k}+1}, u_{m_{k}+1}\right)=\max \left\{d\left(u_{n_{k}}, u_{m_{k}}\right), d\left(u_{n_{k}}, u_{n_{k}+1}\right),\right. \\
\left.d\left(u_{m_{k}}, u_{m_{k}+1}\right), \frac{d\left(u_{n_{k}}, u_{m_{k}+1}\right)+d\left(u_{m_{k}}, u_{n_{k}+1}\right)}{2}\right\} .
\end{gathered}
$$

By (21), we observe that

$$
\begin{aligned}
& \lim _{k \rightarrow \infty} \frac{d\left(u_{n_{k}}, u_{m_{k}+1}\right)+d\left(u_{m_{k}}, u_{n_{k}+1}\right)}{2} \\
& \quad \leq \lim _{k \rightarrow \infty} \frac{d\left(u_{n_{k}}, u_{m_{k}}\right)+d\left(u_{m_{k}}, u_{m_{k}+1}\right)+d\left(u_{m_{k}}, u_{n_{k}}\right)+d\left(u_{n_{k}}, u_{n_{k}+1}\right)}{2} \\
& \quad \leq \lim _{k \rightarrow \infty} d\left(u_{n_{k}}, u_{m_{k}}\right),
\end{aligned}
$$

and, as a consequence,

$$
\begin{aligned}
& \lim _{k \rightarrow \infty} d\left(u_{n_{k}}, u_{m_{k}}\right) \leq \lim _{k \rightarrow \infty} M\left(u_{n_{k}}, u_{m_{k}}, u_{n_{k}+1}, u_{m_{k}+1}\right) \\
& =\max \left\{\lim _{k \rightarrow \infty} d\left(u_{n_{k}}, u_{m_{k}}\right), \lim _{k \rightarrow \infty} d\left(u_{n_{k}}, u_{n_{k}+1}\right), \lim _{k \rightarrow \infty} d\left(u_{m_{k}}, u_{m_{k}+1}\right),\right. \\
& \left.\lim _{k \rightarrow \infty} \frac{d\left(u_{n_{k}}, u_{m_{k}+1}\right)+\left(d u_{m_{k}}, u_{n_{k}+1}\right)}{2}\right\} \leq \lim _{k \rightarrow \infty} d\left(u_{n_{k}}, u_{m_{k}}\right) .
\end{aligned}
$$

Hence, (25) implies that $\lim _{k \rightarrow \infty} M\left(u_{n_{k}}, u_{m_{k}}, u_{n_{k}+1}, u_{m_{k}+1}\right)$ $=\lim _{k \rightarrow \infty} d\left(u_{n_{k}}, u_{m_{k}}\right)=\varepsilon>0$. Then, by (28) and (30), we obtain that

$$
\begin{aligned}
1 & =\lim _{k \rightarrow \infty} \frac{d\left(u_{n_{k}+1}, u_{m_{k}+1}\right)}{M\left(u_{n_{k}}, u_{m_{k}}, u_{n_{k}+1}, u_{m_{k}+1}\right)} \\
& \leq \lim _{k \rightarrow \infty} \beta\left(M\left(u_{n_{k}}, u_{m_{k}}, u_{n_{k}+1}, u_{m_{k}+1}\right)\right) \leq 1 .
\end{aligned}
$$

By the property of $\beta$, we obtain that

$$
0<\lim _{n \rightarrow \infty} d\left(u_{n_{k}}, u_{m_{k}}\right)=\lim _{n \rightarrow \infty} M\left(u_{n_{k}}, u_{m_{k}}, u_{n_{k}+1}, u_{m_{k}+1}\right)=0,
$$

a contradiction. Therefore, we can conclude that $\left\{u_{n}\right\}$ is a Cauchy sequence.

The essential observation is that $\left\{u_{n}\right\}$ is a Cauchy sequence in the closed subset $A_{0}$ of the complete metric space $X$. Then, there exists $u \in A_{0}$ such that $\lim _{n \rightarrow \infty} u_{n}=u$. Consider, by (11) and (12), that $d\left(u_{n}, S x_{n}\right)=d\left(u_{n-1}, T x_{n}\right)=d(A, B)$. Since $S$ and $T$ commute proximally,

$$
S u_{n-1}=T u_{n}
$$

for all $n \geq 1$. By the continuity of $S$ and $T$,

$$
S u=\lim _{n \rightarrow \infty} S u_{n-1}=\lim _{n \rightarrow \infty} T u_{n}=T u .
$$

We are now in a position to show that a best proximity coincidence point of $(S, T)$ exists. Since $S\left(A_{0}\right) \subseteq B_{0}$, there exists $x^{*} \in A_{0}$ such that

$$
d\left(x^{*}, T u\right)=d\left(x^{*}, S u\right)=d(A, B) .
$$

By the assumption that $S$ and $T$ commute proximally, $S$ $x^{*}=T x^{*}$. According to the assumption that $S\left(A_{0}\right) \subseteq B_{0}$, there exists $z^{*} \in A_{0}$ such that

$$
d\left(z^{*}, T x^{*}\right)=d\left(z^{*}, S x^{*}\right)=d(A, B) .
$$

Next, we claim that $x^{*}=z^{*}$. Suppose that $x^{*} \neq z^{*}$, i.e., $d$ $\left(x^{*}, z^{*}\right)>0$. We observe that

$$
\begin{aligned}
M\left(x^{*}, z^{*}, x^{*}, z^{*}\right) & =\max \left\{d\left(x^{*}, z^{*}\right), d\left(x^{*}, x^{*}\right), d\left(z^{*}, z^{*}\right)\right\}=d\left(x^{*}, z^{*}\right), \\
d\left(x^{*}, z^{*}\right) \leq & \beta\left(M\left(x^{*}, z^{*}, x^{*}, z^{*}\right)\right) M\left(x^{*}, z^{*}, x^{*}, z^{*}\right) \\
= & \beta\left(d\left(x^{*}, z^{*}\right)\right) d\left(x^{*}, z^{*}\right) \leq d\left(x^{*}, z^{*}\right) .
\end{aligned}
$$

Since $d\left(x^{*}, z^{*}\right)>0$, we have $1 \leq \beta\left(d\left(x^{*}, z^{*}\right)\right) \leq 1$. By the property of $\beta, d\left(x^{*}, z^{*}\right)=0$. This contradicts the assumption that $x^{*} \neq z^{*}$. Thus, $x^{*}=z^{*}$, and hence

$$
d\left(x^{*}, S x^{*}\right)=d(A, B)=d\left(x^{*}, T x^{*}\right) .
$$

That is, the element $x^{*} \in A$ is a common best proximity coincidence point of $(S, T)$.

Finally, we have to show that the point $x^{*}$ is unique.

Let $y^{*} \in A$ be a common best proximity coincidence point of $(S, T)$. Then

$$
d\left(x^{*}, S x^{*}\right)=d\left(y^{*}, S y^{*}\right)=d(A, B)=d\left(x^{*}, T x^{*}\right)=d\left(y^{*}, T y^{*}\right) .
$$

Notice that $M\left(x^{*}, y^{*}, x^{*}, y^{*}\right)=\max \left\{\left(d x^{*}, y^{*}\right), d\left(x^{*}, x^{*}\right)\right.$, $\left.d\left(y^{*}, y^{*}\right)\right\}=d\left(x^{*}, y^{*}\right)$. Since $(S, T)$ is dominating proximal generalized Geraghty, we obtain that

$$
d\left(x^{*}, y^{*}\right) \leq \beta\left(d\left(x^{*}, y^{*}\right)\right) d\left(x^{*}, y^{*}\right) \leq d\left(x^{*}, y^{*}\right) .
$$

If $d\left(x^{*}, y^{*}\right)>0$, then $\beta\left(d\left(x^{*}, y^{*}\right)\right)=1$, and so, by using the property of $\beta$,

$$
d\left(x^{*}, y^{*}\right)=0,
$$

a contradiction. Thus, $d\left(x^{*}, y^{*}\right)$ must be zero. As a result, $x^{*}=y^{*}$. The proof is now completed.

Example 5. Let $X=\mathbb{R}^{2}$ equipped with the metric $d$ given by

$$
d\left(\left(x_{1}, y_{1}\right),\left(x_{2}, y_{2}\right)\right)=\sqrt{\left(x_{1}-x_{2}\right)^{2}+\left(y_{1}-y_{2}\right)^{2}} .
$$


Let $A=\{(x, 1): 0 \leq x \leq 5\}$ and $B=\{(x,-1): 0 \leq x \leq 5\}$. It is easy to see that $d(A, B)=2$. Define the mappings $S, T: A$ $\longrightarrow B$ by

$$
S(x, 1)=(\ln (1+x),-1) \text { and } T(x, 1)=(x,-1),
$$

for all $(x, 1) \in A$. Notice that $S$ and $T$ are continuous. To show that the pair $(S, T)$ is dominating proximal generalized Geraghty, define the mapping $\beta:[0, \infty) \longrightarrow[0,1]$ by

$$
\beta(t)= \begin{cases}1, & t=0 \\ \frac{\ln (1+t)}{t}, & t>0\end{cases}
$$

Then, $\beta \in \mathscr{B}$. Let $x_{1}, x_{2}, u_{1}, u_{2}, v_{1}, v_{2} \in A$ satisfying

$$
d\left(u_{1}, S x_{1}\right)=d\left(u_{2}, S x_{2}\right)=d(A, B)=d\left(v_{1}, T x_{1}\right)=d\left(v_{2}, T x_{2}\right) .
$$

Observe that they must have the following forms:

$$
\begin{aligned}
& x_{1}=\left(\widehat{x}_{1}, 1\right), x_{2}=\left(\widehat{x}_{2}, 1\right), u_{1}=\left(\widehat{u}_{1}, 1\right), \\
& u_{2}=\left(\widehat{u}_{2}, 1\right), v_{1}=\left(\widehat{v}_{1}, 1\right), v_{2}=\left(\widehat{v}_{2}, 1\right),
\end{aligned}
$$

where $\widehat{u}_{1}=\ln \left(1+\widehat{x}_{1}\right), \widehat{u}_{2}=\ln \left(1+\widehat{x}_{2}\right), \widehat{v}_{1}=\widehat{x}_{1}, \widehat{v}_{2}=\widehat{x}_{2}$, and $\widehat{x}_{1}, \widehat{x}_{2} \in[0,5]$. To obtain the inequality (9), if $u_{1}=u_{2}$, then we are done. Assume that $u_{1} \neq u_{2}$. Then, $\widehat{u}_{1}, \widehat{u}_{2}, \widehat{v}_{1}$, and $\widehat{v}_{2}$ are all distinct. As a consequence, $M\left(v_{1}, v_{2}, u_{1}, u_{2}\right)>0$. Thus, we have that

$$
\begin{aligned}
d\left(u_{1}, u_{2}\right) & =\left|\widehat{u}_{1}-\widehat{u}_{2}\right|=\left|\ln \left(1+\widehat{v}_{1}\right)-\ln \left(1+\widehat{v}_{2}\right)\right| \\
& =\left|\ln \left(\frac{1+\widehat{v}_{2}+\widehat{v}_{1}-\widehat{v}_{2}}{1+\widehat{v}_{2}}\right)\right| \leq \ln \left(1+\left|\widehat{v}_{1}-\widehat{v}_{2}\right|\right) \\
& \leq \ln \left(1+M\left(v_{1}, v_{2}, u_{1}, u_{2}\right)\right) \\
& =\left[\frac{\ln \left(1+M\left(v_{1}, v_{2}, u_{1}, u_{2}\right)\right)}{M\left(v_{1}, v_{2}, u_{1}, u_{2}\right)}\right] M\left(v_{1}, v_{2}, u_{1}, u_{2}\right) \\
& =\beta\left(M\left(v_{1}, v_{2}, u_{1}, u_{2}\right)\right) M\left(v_{1}, v_{2}, u_{1}, u_{2}\right) .
\end{aligned}
$$

Therefore, the pair $(S, T)$ is dominating proximal generalized Geraghty.

Next, consider, by the definition of $A_{0}$ and $B_{0}$, that $A_{0}=A$ and $B_{0}=B$. Additionally,

$S\left(A_{0}\right)=\{(x,-1): 0 \leq x \leq \ln 6\} \subseteq\{(x,-1): 0 \leq x \leq 5\}=B_{0}=T\left(A_{0}\right)$.

Now, it remains to show that $S$ and $T$ commute proximally. Let $x, u, v \in A$ such that

$$
d(u, S x)=d(v, T x)=d(A, B)
$$

Consequently, $x=(\widehat{x}, 1), u=(\widehat{u}, 1), v=(\widehat{v}, 1)$, where $\widehat{u}=$ $\ln (1+\hat{x})$ and $\widehat{v}=\widehat{x}$. Thus,

$$
S v=(\ln (1+\widehat{v}),-1)=(\ln (1+\widehat{x}),-1)=(\widehat{u},-1)=T u \text {. }
$$

Thus, $S$ and $T$ commute proximally.

Finally, by Theorem 4, we can conclude that there is a unique common best proximity coincidence point of the pair $(S, T)$. In fact, the point $(0,1)$ is the unique common best proximity coincidence point of $(S, T)$.

As a consequence of our result, the following corollaries are given. Precisely, these are the special cases of Theorem 4 when $\beta(t)=k$ for $k \in[0,1)$, and $\beta(t)=e^{-k t}$ for $k>0$, respectively.

Corollary 6. Let $(A, B)$ be a pair of nonempty subsets of a complete metric space $(X, d)$. Assume that $A_{0}$ and $B_{0}$ are nonempty such that $A_{0}$ is closed. If $S, T: A \longrightarrow B$ are mappings such that the following assertions hold:

(1) $S\left(A_{0}\right) \subseteq B_{0}$ and $S\left(A_{0}\right) \subseteq T\left(A_{0}\right)$

(2) $S$ and $T$ are continuous

(3) $S$ and $T$ commute proximally

(4) There exists $k \in[0,1)$ such that for each $x_{1}, x_{2}, u, v, x$, $y \in A$

$$
d\left(u, S x_{1}\right)=d\left(v, S x_{2}\right)=d(A, B)=d\left(x, T x_{1}\right)=d\left(y, T x_{2}\right)
$$

implies

$$
d(u, v) \leq k M(x, y, u, v)
$$

where $M(x, y, u, v)=\max \{d(x, y), d(x, u), d(y, v),((d(x, v)$ $+d(y, u)) / 2)\}$, then there is a unique common best proximity coincidence point $x^{*} \in A$ of the pair $(S, T)$.

Corollary 7. Let $(A, B)$ be a pair of nonempty subsets of a complete metric space $(X, d)$. Assume that $A_{0}$ and $B_{0}$ are nonempty such that $A_{0}$ is closed. If $S, T: A \longrightarrow B$ are mappings such that the following assertions hold:

(1) $S\left(A_{0}\right) \subseteq B_{0}$ and $S\left(A_{0}\right) \subseteq T\left(A_{0}\right)$

(2) $S$ and $T$ are continuous

(3) S and T commute proximally

(4) There exists $k>0$ such that for each $x_{1}, x_{2}, u, v, x, y$ $\in A$

$$
d\left(u, S x_{1}\right)=d\left(v, S x_{2}\right)=d(A, B)=d\left(x, T x_{1}\right)=d\left(y, T x_{2}\right)
$$

implies

$$
d(u, v) \leq e^{-k M(x, y, u, v)} M(x, y, u, v),
$$


where $M(x, y, u, v)=\max \{d(x, y), d(x, u), d(y, v),((d(x, v)$ $+d(y, u)) / 2)\}$, then there is a unique common best proximity coincidence point $x^{*} \in A$ of the pair $(S, T)$.

\section{Conclusion}

In this work, we give an idea of dominating proximal generalized Geraghty for a pair of mappings and give the existence and uniqueness theorem for a common best proximity coincidence point of these pairs in a complete metric space with some extra assumptions. Further, we present an example of this result. Now, we pose the following open problem.

Open Problem 1. Can Theorem 4 be extended to the framework of complete metric spaces endowed with graphs?

\section{Data Availability}

No data were used to support this study.

\section{Conflicts of Interest}

The authors have no conflict of interests regarding the publication of this paper.

\section{Acknowledgments}

The author would like to give special thanks to Assistant Professor Phakdi Charoensawan for all of his useful comments and suggestions. This research was partially supported by Chiang Mai University.

\section{References}

[1] K. Fan, "Extensions of two fixed point theorems of F.E. Browder," Mathematische Zeitschrift, vol. 112, no. 3, pp. 234-240, 1969.

[2] S. Reich, "Approximate selections, best approximations, fixed points, and invariant sets," Journal of Mathematical Analysis and Applications, vol. 62, no. 1, pp. 104-113, 1978.

[3] S. S. Basha and P. Veeramani, "Best proximity pair theorems for multifunctions with open fibres," Journal of Approximation Theory, vol. 103, no. 1, pp. 119-129, 2000.

[4] W. A. Kirk, S. Reich, and P. Veeramani, "Proximinal retracts and best proximity pair theorems," Numerical Functional Analysis and Optimization, vol. 24, no. 7-8, pp. 851-862, 2003.

[5] A. A. Eldred and P. Veeramani, "Existence and convergence of best proximity points," Journal of Mathematical Analysis and Applications, vol. 323, no. 2, pp. 1001-1006, 2006.

[6] P. Cholamjiak and S. Suantai, "Strong convergence for a countable family of strict pseudocontractions in q-uniformly smooth Banach spaces," Computers \& Mathematcs with Applications, vol. 62, no. 2, pp. 787-796, 2011.

[7] E. Karapinar and I. M. Erhan, "Best proximity point on different type contractions," Applied Mathematics \& Information Sciences, vol. 3, pp. 342-353, 2011.

[8] E. Karapınar and S. Kishin, "Fixed point theory for cyclic weak $\phi$-contraction," Applied Mathematics Letters, vol. 24, no. 6, pp. 822-825, 2011.

[9] P. Cholamjiak and S. Suantai, "Viscosity approximation methods for a nonexpansive semigroup in Banach spaces with gauge functions," Journal of Global Optimization, vol. 54, no. 1, pp. 185-197, 2012.

[10] E. Karapınar, "Best proximity points of Kannan type cylic weak $\phi$-contractions in ordered metric spaces," Analele Universitatii" Ovidius" Constanta-Seria Matematica, vol. 20, no. 3, pp. 51-64, 2012.

[11] E. Karapinar, "Best proximity points of cyclic mappings," Applied Mathematics Letters, vol. 25, no. 11, pp. 1761-1766, 2012.

[12] S. Suantai, W. Cholamjiak, and P. Cholamjiak, "An implicit iteration process for solving a fixed point problem of a finite family of multi-valued mappings in Banach spaces," Applied Mathematics Letters, vol. 25, no. 11, pp. 1656-1660, 2012.

[13] E. Karapınar, V. Pragadeeswarar, and M. Marudai, "Best proximity point for generalized proximal weak contractions in complete metric space," Journal of Applied Mathematics, vol. 2014, Article ID 150941, 6 pages, 2014.

[14] E. Karapınar, "On best proximity point of $\psi$-Geraghty contractions," Fixed Point Theory and Application, vol. 2013, no. 1, 2013.

[15] C. Mongkolkeha, Y. J. Cho, and P. Kumam, "Best proximity points for Geraghtys proximal contraction mappings," Fixed Point Theory and Applications, vol. 2013, no. 1, 2013.

[16] Z. I. AL-Muhiameed, M. Bousselsal, M. L. Kadri, and S. H. Jah, "A generalization of Geraghtys theorem in partially ordered G-metric spaces and application to ordinary differential equations," Nonlinear Functional Analysis and Applications, vol. 19, no. 3, pp. 359-377, 2014.

[17] E. Karapinar and B. Samet, "A note on ' $\psi$-Geraghty type contractions,", Fixed Point Theory and Applications, vol. 2014, no. $1,2014$.

[18] W. Cholamjiak, P. Cholamjiak, and S. Suantai, "Convergence of iterative schemes for solving fixed point problems for multi-valued nonself mappings and equilibrium problems," Journal of Nonlinear Sciences and Applications, vol. 8, no. 6, pp. 1245-1256, 2015.

[19] E. Karapinar and F. Khojasteh, "An approach to best proximity points results via simulation functions," Journal of Fixed Point Theory and Applications, vol. 19, no. 3, pp. 1983-1995, 2017.

[20] N. Bunlue and S. Suantai, "Best proximity point for proximal Berinde nonexpansive mappings on starshaped sets," Archivum Mathematicum, vol. 54, no. 3, pp. 165-176, 2018.

[21] N. Bunlue and S. Suantai, "Hybrid algorithm for common best proximity points of some generalized nonself nonexpansive mappings," Mathematicsl Methods in the Applied Sciences, vol. 41, no. 17, pp. 7655-7666, 2018.

[22] P. Sarnmeta and S. Suantai, "Existence and convergence theorems for best proximity points of proximal multi-valued nonexpansive mappings," Communications in Mathematics and Applications, vol. 10, no. 3, pp. 369-377, 2019.

[23] R. Suparatulatorn and S. Suantai, "A new hybrid algorithm for global minimization of best proximity points in Hilbert spaces," Carpathian Journal of Mathematics, vol. 35, no. 1, pp. 95-102, 2019.

[24] M. A. Geraghty, "On contractive mappings," Proceedings of the American Mathematical Society, vol. 40, no. 2, pp. 604-608, 1973.

[25] S. Sadiq Basha, "Common best proximity points: global minimization of multi-objective functions," Journal of Global Optimization, vol. 54, no. 2, pp. 367-373, 2012. 
[26] P. Kumam and C. Mongkolekeha, "Common best proximity points for proximity commuting mapping with Geraghtys functions," Carpathian Journal of Mathematics, vol. 31, no. 3, pp. 359-364, 2015.

[27] L. Chen, "Common best proximity points theorems," Journal of Management Research and Analysis, vol. 39, no. 3, pp. 289-294, 2019.

[28] M. I. Ayari, "A best proximity point theorem for $\alpha$-proximal Geraghty non-self mappings," Fixed Point Theory and Applications, vol. 2019, no. 1, 2019.

[29] S. Sadiq Basha, N. Shahzad, and R. Jeyaraj, "Common best proximity points: global optimization of multi- objective functions," Applied Mathematics Letters, vol. 24, no. 6, pp. 883886, 2011. 